\title{
Menstruation and its Social Implications on Un-Married Adolescent Girls: A Case Study of Village Tarayyia, District Rawalpindi
}

\author{
Noor-Us-Sehar ${ }^{1 *}$, Nasser Mohuddin ${ }^{2}$ \\ ${ }^{1} \mathrm{Ph} . \mathrm{D}$. Scholar, Islamabad, PAKISTAN \\ ${ }^{2}$ CEO, National Trust for Population Welfare Islamabad, PAKISTAN \\ *Correspondence (Email): \\ religion678@hotmail.com
}

\begin{abstract}
The paper presents research findings on menarche and developments associated with it. This particular village was chosen on account of being traditional with some development and its link with the city. Menarche is regarded as sign for restrictions to be imposed on girls, which deprives them from their basic rights. The authority and autonomy of these girls is almost nil as there are no windows of opportunities for them, this is all culturally constructed and there is change coming but with a slow pace. There are a few cases that show that females when provided with an opportunity have done well but these were only possible in special circumstances, for all the adolescent girls means have to be explored for bringing them up on a common ground from where they can find ways.
\end{abstract}

Key words: mobility, reproductive role, rights, female authority

\section{INTRODUCTION}

The Constitution of the Islamic Republic of Pakistan clearly spells the rights bestowed by Islam for the women and girls. The article 25 of the Constitution talks in terms of rights that can be exercised by all citizens of the state. Yet women and girls face a number of consequences regarding decisions taken for them by the male members of the family, society and cultures that are further reinforcing these complex phenomena. The impacts are many folded but at this particular point in time the paper intends to look at the occurrence of menarche and its consequences in the lives of adolescent girls in a rural, traditional society.

In a traditional society, the appearance of first menstrual cycle, brings the girl from child to the adult status, where there is a great concern regarding sexuality. This is also a kind of rite of passage for her, and from now on there will be strict eye on her mobility, which is also controlled. In a few decades back, this was regarded as a sign of her maturity and in many cases the elderly women reported that their marriage was arranged accordingly.

There are three aspects of concern, when we look at the girl's life; there is the issue of her health, the cultural part attached with decisions about it and the right that is bestowed in her as a member of a society. For an unmarried girl the issues are different from those that a married adolescent woman faces. Hence the society has provided little space for her to benefit from decisions regarding her health.

According to the Pakistan Demographic and Health Survey (NIPS, 2007), Pakistan has a very high profile of young population- i.e. to say that 41 percent of the population is below the age 15 and only 4 percent of the population is over 65 years of age.

It is a fact that in a patrilineal society, major decisions are made by the head of the house-hold. But the decisions taken are also dependent on their kind, e.g.; in case of female adolescents the decision regarding her mobility will be addressed by the father, elder-brother and mother. But on the occasion of a girls first menarche the mother or the 
elder daughter, will be the ones who will take a decision, what to tell, when to tell, who would take the lead, and how much information should be shared with this girl.

James .G. M (1994) has, come up with an explanation of how decisions are taken. According to his definition, decision making is said to be a cognitive process, which leads to the selection of course of actions among alternatives. It is also important to bring into this discussion the significant role a culture plays for the person or persons taking or adopting a decision, further it varies from culture to culture the kind of space and available options for adolescents.

Decisions that are taken by the members of a society, family or an individual are largely dependent upon the status of a person and the role that emerges as a result of this status. In other words it can be said that it is a power game, and in a patrilineal male dominated society this power vests in the hands of the males. But again it is important to see what decisions are made by males and where in this process can a female play her role.

\section{Methodology}

A socio-economic survey of the village was conducted, each house was reached and necessary information was gathered. The total population of the village is 2071. Applying the stratified sampling technique, the adolescent population between 10- 19 was recorded. This was further divided into three groups to see the level of information with reference to age factor. The groups comprised of, G1 (10-11-12), G2 (13-14-15), G3 (16-17-18-19) the main focus of research was age group, G2, who were the females that had experienced menstruation process and G3 that had both the married and un-married adolescents. The selection criteria of the respondents were based on those females who had experienced first menstruation, were either married or un -married and were willing to participate. In order to view the change across three generations, focus group discussions were held at three levels M1 (adolescent girls), M2.

The meaning of puberty for traditional and non industrialized societies is also different as compared to the developed and industrialized societies. For the traditional societies this is a signal for entering into the reproductive role, whereas for the industrialized nations, it is a time to learn skills and become able to fit into the technical world and find a suitable role for oneself.

Similarly in the context of the present study, the girl child, when enters into biological puberty, there are social restrictions that are imposed on her, and all this relates to the control of sexuality, as in this culture the aspect of virginity among the females is of special significance. No one will accept a girl for a marriage, if they learn about her involvement in any kind of sexual activity either by force or will. Her virginity is of special significance and there are no acceptable ways in any form where she can be excused.

Schelegal (1985) has argued on the social functions of adolescence across cultures is to prepare them for their reproductive role. Some two decades back, it was believed by the elders of this village that menstruation in girls was a signal that they are ready for their reproductive role. With the advancement of roads, electricity and links of villagers with city around them the idea that emerged was that there are other avenues for girls rather than just marriages. As the examples although limited in number show that some bold steps taken by head of households have demonstrated that girls when given the opportunity to study and learn skills have proved very fruitful.

Khan etal (2013) has looked at various issues of reproductive health and health seeking behavior of the adolescent girls. She stated that menstruation means a lot in the life of a girl, her mobility is controlled and this is also a sign that she can be tied into a marriage bond within the coming few years. (Two years).

\begin{tabular}{|c|c|c|c|}
\hline Sr. No & $\begin{array}{c}\text { Adolescents } \\
(10-12 \text { Years) }\end{array}$ & $\begin{array}{c}\text { Adolescents } \\
\text { (13-15 Years) and (16-19 Years ) }\end{array}$ & $\begin{array}{c}\text { Total Adolescents } \\
\text { (10-19 Years) }\end{array}$ \\
\hline 1 & 85 & 169 & 254 \\
\hline
\end{tabular}

Decisions take place at the level of the family, and the head of the household will decide, in the light of his traditions what is good for the family. Girls and boys are treated separately by the same individual. If there is puberty process for a girl, her mobility is restricted, whereas the male adolescent will be allowed to go out and do the outdoor activities. The females are restricted to the household space, and this restriction will in future limit them to many new openings that can bring about a change in her life. If the school is located in a far off place from the residence it will create an impact that limits the access to get education. Some very interesting case studies have been recorded that have clearly demonstrated that in cases where the adolescent girls had the opportunity to be mobile and decisions were favorable for them, they have come up with remarkable achievements in their lives.

As soon as the girl enters into her puberty, she experiences her first menarche; the issue is of great importance for the family. The virginity of the girl is taken special care, and she is now been closely watched. A lot of restrictions are imposed on her, and the most important one is regarding her mobility. This is how her sexuality is controlled. In this culture there are no sexual relations found among the un- married adolescent girls or boys. It is strictly 
forbidden, taken care of and taboos and norms are set to control this. Study of value of virginity as reported by Schlegel etal (1991) is an important view, she states that those societies that give dowry, place a lot of value in virginity. This is a true fact as far as she has observed, but in this traditional society, the same meaning cannot be drawn. Virginity as discussed with the community also has a religious connotation attached and it is a sin accordingly to indulge in extra marital sex, before and after marriage with other partners except husband and wife. The community at large does not support illicit relations and deviance is dealt with punishment and shame. No concept exists of children born out of wed lock, hence all these restrictions have their own context, and everything is done to control it.

The group discussions with the young adolescent girls showed their keen interest in learning skills that are technical in nature; these include sewing, embroidery, and stitching. There is no proper formal learning institute. Compared to urban technical schools where a vast number of skills are taught to girls. These girls have a limited vision and are focused around sewing and stitching, which can help them in future when they have a family life. At the time of research they also mentioned computer learning, but this was difficult as no female teacher was available. Going to city for learning this skill meant that they need approval and assistance from father or elder brother. Hence there is awareness and desire to learn skills but virtually no options were available locally as the community had no such resources of its own that could encourage girls to learn skills.

Female authority and autonomy in the domestic domain is very minimal as far as the major decisions are concerned. It is also related to the age, gender, marital status and seniority in the family or amongst a group of relations. In house-hold which is nuclear, the main authority figure is the father; the mother will have certain restrictions on certain issues, but in some others that are not of major concern, like house-hold affairs, gift-giving, domestic budget, etc., she can have a leading role. As far as the house-hold budget is concerned it was found during the course of the research, that since she is not an earning member in almost ninety-nine percent cases, she has to adjust her budget within what has been given to her, and she may also be held answerable on the amount spent and purchases made. In some cases it was found that the men keep all the money and bring all the grocery items themselves. In such cases the males have kept a tight hold of all that is spent, and do not give any amount to the wife, because it is believed that their control keeps money from being wasted. The wife can have a say in what she needs and how much, but the husband keeps a watch on all that is spent. Hence from the very first step of the socialization process very submissive attitudes are encouraged by the family institution. There is a direct link between a woman's autonomy and her care seeking behavior. This is also true for other walks of life, because being autonomous also results in taking decisions partially if not wholly in a patrilineal society.

Women with high level of autonomy (Arif etal, 2006) are more likely to have better chances of treatment regarding their own health and also for the new born. There are three areas that have been identified by the research conducted by the Population Council, and these include, levels of participation in decision-making, control over finances and the level of mobility. These three acted like a catalyst for women who had hold over it and it made a lot of difference in comparison with those women who were lacing these. As far as this fact is pointed out, it can also be added that, women in the research area, who were found educated and doing a job, were more autonomous. It was also interesting to note that the house-hold that had no son amongst a group of four to five daughters had more autonomy because the father was also out of the village due to his job. The circumstances were such that the mother had to do her house-hold chores, she needed support from the daughters because there was no other available option for them and hence they became more autonomous. But this was rare, and although it was a factor adding to their autonomy, yet it was an important case as the father was educated and believed that daughter can be like the sons and he provided them with the opportunity.

\section{IMPACT OF MENSTRUATION ON A GIRLS LIFE}

Menstruation brings a lot of change in the social life of a girl. As she was busy playing with her mates in the courtyard, suddenly there is some change reported by her to the mother, she understands that now is the time for a special care of the daughter, because her virginity means a lot in this culture. She is taken care in the same manner as she was handled when she was a child. She now has to learn that there is a change in the social status; she is no more regarded as a child, rather a grownup who has to behave in the same manner.

\section{Mobility Issue}

There is a great concern regarding the mobility issue for girls, now she must not go out, if she has to go to school someone must accompany her like a brother, father or mother. If the school is not within the village as in this particular case only primary classes were within the said locale and secondary school was located far away, then it is preferred to keep them at home rather sending them far-off, because who will accompany them.

\section{Purdah}

The girl is required to cover her body properly and no one should see her in an improper dress. When she is twelve years old the mother gets vigilant about her menstruation and keeps an eye on the girls, she advises the daughter to be vigilant in keeping herself fully covered, this is also a sign of entering puberty and maturity. 


\section{Reproductive Role}

Some two decades back the menstruation of a girl was a signal for the parents to think of her as eligible for her secondary role, i.e. tying her up in the marriage bond, but with the passage of time, as there were new avenues for girls, like the opening of a school, the parents thought of other options. The typical role came with a twist in the life of these girls.

\section{Distancing from Males}

As soon as the adolescent girl enters into puberty and has the first cycle, the main issue surrounding her family is to protect her virginity and keep her safe. In this regard she is strictly watched and is not allowed to mingle and talk to males, like her cousins, boys in the neighbor hood and so on. When she was a minor girl she enjoyed talking to her relatives and played in the nearby surroundings, which are no more open for her.

\section{CONCLUSION}

The cultural construct around puberty and its implications means a lot in the lives of adolescent girls that live and grow in traditional societies governed by strict norms and taboos. The situation becomes gloomier when there are no opportunities like education and skill development that can enhance the social status of these girls. The autonomy and authority of such females rests in the hand of elders, who believe that it is better to tie them into the marriage union rather than to sit and protect their virginity. This gesture closes all avenues in the life of these girls who had many dreams to be fulfilled.

\section{REFERENCES}

Arif, S M ,et.al. (2006). Changes in Knowledge and Behavior of Women and Families. SMART Report 3. Population Council Hunter, D.E. and Whitten, P. (1976). Encyclopedia of anthropology: New York: Harper and Row Publishers. International Conference on Population and Development, (1994) Cairo

James, G.M. (1994). A Premier on Decision- Making: How Decisions happen. New York: Free Press Khan, Ayesh and Pine, Pamela. (2003) Adolescents reproductive Health in Pakistan: Policy Project Layton, R. (1997). An Introduction to Theory in Anthropology. Cambridge University Press.

Manual of National Standards for Family Planning Services, (2010). Government of Pakistan. Nardi, B. (1983). Goals in reproductive decision making. American Ethnologist 3: 697-714.

NIPS (2007). Pakistan Demographic and Health Survey (2006-2007). Islamabad: National Institute of Population Studies NIPS (2003). Reproductive Health of Youth: Perceptions, Attitudes and Practices 2003. Islamabad:National Institute of Population Studies.

Personal Hygiene and Reproductive Health Issues of Adolescent. (1998). Ministry of Population Welfar and UNFPA. Sargent, F.C. and Johnson, T.M. (eds.) (1996). Hand Book of Medical Anthropology: Contemporary Theory and Method. West Port: Greenwood Press.

Schelegal. A.(1985); Adolescence :Ethos, volume 23.No:1

Schlegel, Alice and Barry 1ll, (1991): Adolescence, An anthropological inquiry. New York, Free Press. 